\title{
Stock Discrimination of Capelin (Mallotus villosus) in the Northwest Atlantic
}

\author{
R. K. Misra \\ Fisheries Research Branch, Department of Fisheries and Oceans \\ P. O. Box 550, Halifax, Nova Scotia, Canada B3J 257 \\ and \\ J. E. Carscadden \\ Fisheries Research Branch, Department of Fisheries and Oceans \\ Northwest Atlantic Fisheries Centre, P. O. Box 5667 \\ St. John's, Newfoundland, Canada A1C 5X1
}

\begin{abstract}
Although capelin is an important commercial and forage species of the Newfoundland region, firm evidence for the designation of separate stocks does not exist. In a previous analysis of meristic characters of capelin, the authors assumed that meristic data were multivariate normal, an assumption that is not usually met. Consequently, the data were reanalyzed by using non-parametric methodology to assess differences in meristic characters, and the results of the analyses were examined to determine the relative importance of individual characters in the separation of stocks.

Groups of capelin samples from five areas were tested by using 11 meristic characters in two age-groups. Capelin from western Newfoundland and Southeast Shoal of the Grand Bank continued to be clearly identified as separate stocks. The delineations of capelin from the other three areas were less clear, although independent paired comparisons with age combined differentiated the Labrador-Northeast Newfoundland and the northern Grand Bank-Avalon stocks, and separate analysis of age 3 and 4 capelin indicated that these two stocks were different from the St. Pierre Bank stock.
\end{abstract}

\section{Introduction}

Capelin (Mallotus villosus) is considered one of the most important forage species in the Northwest Atlantic. Although it was the object of a small domestic fishery for decades, only in the last decade has it achieved any significance as a commercial species. During the 1970's, capelin were taken in a large international offshore fishery and more recently they have been taken in a Newfoundland based inshore fishery to satisfy the lucrative market for capelin roe in Japan. Despite the importance of capelin as a commercial and a forage species, firm evidence for the existence of several stocks of capelin does not exist, although there are considerable circumstantial data on which tentative stock divisions have been made. Carscadden and Misra (1980) examined differences among five tentatively-designated stocks, including four suggested by Campbell and Winters (1973), based on multivariate analysis of data on 11 meristic characters.

Multivariate methods which are generally used, including those used by Carscadden and Misra (1980), are based on the assumption that the data are multivariate normal. This is not true for meristic data, because these are discrete counts over a narrow range. Recently, Bowering and Misra (1982) presented a multivariate generalized-distance method (including a FORTRAN IV computer program) which is appropriate for comparing populations based on meristic data. This method does not require that meristic data be multivariate normal. Consequently, it was considered appropriate to reanalyze the capelin data (with some minor exclusions) of Carscadden and Misra (1980) by using the new methodology. Frequency distributions of meristic counts may not always be identical for two age-groups due to sampling variability. To reduce ambiguity in interpreting the results of analysis for differences between stocks, which may occur if patterns of variation are different in the two age-groups, it was considered useful to analyze the data separately for each age-group as well as for ages combined. The results were examined also to determine the relative importance of individual meristic characters in the separation of the capelin stocks.

\section{Methods and Materials}

The new method and computer program were described by Bowering and Misra (1982), and, therefore, only a brief outline of the procedures is given here. Two measures of generalized distance, designated $B^{2}$ and $\mathrm{G}^{2}$ and based on "within" and "total" covariance matrices respectively, are employed. These measures generally yield results which are remarkably similar (Kurczynski, 1970; Bowering and Misra, 1982), as is indeed the case with the analysis of capelin data 
reported here. Differences between $B^{2}$ and $G^{2}$ are essentially theoretical in nature with little practical significance. The findings of Bowering and Misra (1982), based on these procedures, agreed remarkably well with the results of Fairbairn (1981) who employed an entirely different technique for stock identification.

Counts of meristic character $(\mathrm{j})$ yield a multinomial distribution with $S_{j+1}$ classes $\left(S_{j}\right.$ being the number of "independent" classes). Numbers of individuals in the $k$-th class of $j$-th character in the $i$-th population $\left(P_{i}\right)$ may be expressed as the proportion $\left(P_{i j k}\right)$ of the total number of individuals in $\mathrm{P}_{\mathrm{i}}$. Class proportions for the $j$-th character of the sample from $P_{i}$ may be employed to construct a histogram. The shape of this histogram will be determined by the distribution of class frequencies for that character. This methodology tests the significance of differences between these distributions, assigns numerical values to distances between them and thereafter ranks the samples. Generalizeddistance analysis of characters, considered first individually and then collectively, is conducted on the basis of a two-way (population $\times$ class) layout. The computer program (Bowering and Misra, 1982) provides for analysis of mutually correlated characters by multiple classification procedure. The program tests the significance of Spearman's coefficient of rank correlation between characters. This measure of correlation does not require the assumption of a bivariate normal distribution. Even if two characters are correlated, there may be arguments in favor of disregarding the correlation (Bowering and Misra, 1982). Therefore, where characters are considered independent, generalized distance analysis must be done in any case. In addition to the values of $\mathrm{B}^{2}$ and $\mathrm{G}^{2}$, the program calculates values of $x^{2}$ which may be used to rank characters on the basis of their contributions to differences between groups and to rank the groups. The 11 meristic characters $\left(Y_{j}, j=1, \ldots, 11\right)$ reported by Carscadden and Misra (1980) were coded as follows:

1. Left pectoral fin-rays

2. Dorsal fin-rays

3. Anal fin-rays

4. Pyloric caecae

5. Branchiostegals

6. Upper gillrakers

7. Lower gillrakers

8. Dorsal secondary caudal fin-rays

9. Ventral secondary caudal fin-rays

10. Precaudal vertebrae

11. Caudal vertebrae

Carscadden and Mirsa (1980) combined data for capelin age-groups 3 and 4 and compared groups of samples from five different regions (designated groups $A, B, C, D$ and $E$ ) by analyzing data on eight of the meristic characters $(1,2,3,4,6,7,10,11)$. The remaining characters $(5,8,9)$ were excluded from the final analysis because of differences between the two age- groups. In the present study, the data were analyzed by age-groups separately and with ages combined. Fish with no missing observations on all meristic characters were used in the analysis. In addition, three fish were excluded from group A because closer examination of the raw data indicated unusually high counts in some characters. This was considered a conservative approach, because the inclusion of these high counts could enhance any differences between groups.

Sampling locations (No. 1-12) and the five stock areas (groups A-E) are illustrated in Fig. 1. Sample sizes and ranges of meristic counts for the 11 characters, tested in this analysis, are given in Table 1 . The grouping of data by area was the same as that utilized by Carscadden and Misra (1980). Evidence from Canadian, Norwegian and USSR research surveys lead to the belief that mature capelin which occur in Div. $3 \mathrm{~L}$ in early spring represent a mixture of fish that will spawn later in the year in inshore waters of Div. 3L and offshore on the Southeast Shoal (Div. 3N). It may be that other adjacent stocks (e.g. the Northeast Newfoundland-Labrador stock in Div. $2 \mathrm{~J}+3 \mathrm{~K}$ and the northern Grand Bank-Avalon stock in Div. $3 L$ ) mix as

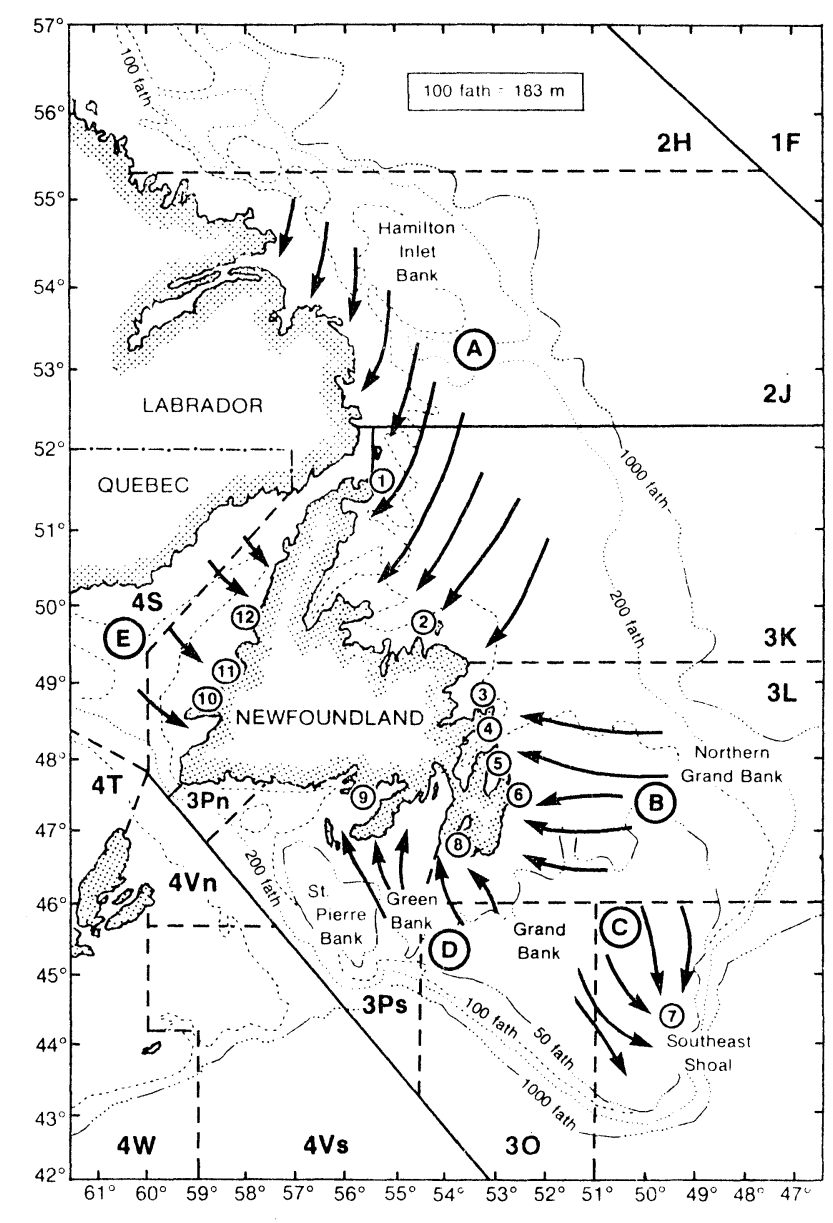

Fig. 1. Capelin sampling locations (1-12) and groups of samples by area $(A-E)$ in the Newfoundland region. (Arrows indicate migration routes of mature capelin to spawning grounds, as proposed by Campbell and Winters, 1973.) 
TABLE 1. Ranges of counts for 11 meristic characters in five groups of capelin (ages 3 and 4) from various parts of the Newfoundland area in June 1976 .

\begin{tabular}{|c|c|c|c|c|c|c|c|c|c|c|c|c|c|c|c|}
\hline \multirow{2}{*}{ Group } & \multirow{2}{*}{$\begin{array}{l}\text { Sampling } \\
\text { location } \\
\text { (Fig. 1) }\end{array}$} & \multirow{2}{*}{$\begin{array}{l}\text { Sampling } \\
\text { period } \\
(1976)\end{array}$} & \multirow{2}{*}{$\begin{array}{l}\text { Age } \\
\text { (yr) }\end{array}$} & \multirow{2}{*}{$\begin{array}{c}\text { No. } \\
\text { of } \\
\text { fish }\end{array}$} & \multicolumn{11}{|c|}{ Ranges of counts by meristic character number (see text) } \\
\hline & & & & & 1 & 2 & 3 & 4 & 5 & 6 & 7 & 8 & 9 & 10 & 11 \\
\hline \multirow[t]{3}{*}{ A } & $1-2$ & 11-28 Jun & 3 & 80 & $18-21$ & $13-15$ & $22-25$ & $4-8$ & $7-10$ & $8-11$ & $25-30$ & $15-19$ & $12-16$ & $41-44$ & $22-25$ \\
\hline & & & 4 & 66 & $18-22$ & $13-15$ & $22-26$ & $4-8$ & $7-9$ & $8-10$ & $26-30$ & $14-18$ & $12-16$ & $40-46$ & $22-25$ \\
\hline & & & $3+4$ & 146 & $18-22$ & $13-15$ & $22-26$ & $4-8$ & $7-10$ & $8-11$ & $25-30$ & $14-19$ & $12-16$ & $40-46$ & $22-25$ \\
\hline \multirow[t]{3}{*}{ B } & $3-6$ & 19-29 Jun & 3 & 193 & $17-21$ & $13-18$ & $20-25$ & $3-9$ & $7-10$ & $8-11$ & $25-31$ & $15-20$ & $12-16$ & $40-46$ & $20-26$ \\
\hline & & & 4 & 205 & $17-21$ & $13-15$ & $22-26$ & $4-8$ & $7-10$ & $8-10$ & $25-30$ & $14-20$ & $11-16$ & $39-47$ & $20-25$ \\
\hline & & & $3+4$ & 398 & $17-21$ & $13-18$ & $20-26$ & $3-9$ & $7-10$ & $8-11$ & $25-31$ & $14-20$ & $11-16$ & $39-47$ & $20-26$ \\
\hline \multirow[t]{3}{*}{ C } & 7 & 25 Jun & 3 & 42 & $18-21$ & $13-14$ & $22-25$ & $4-8$ & $7-10$ & $8-10$ & $25-30$ & $16-19$ & $13-16$ & $41-44$ & $22-25$ \\
\hline & & & 4 & 45 & $18-21$ & $13-15$ & $22-25$ & $4-8$ & $7-10$ & $8-10$ & $24-29$ & $14-20$ & $11-16$ & $40-44$ & $22-28$ \\
\hline & & & $3+4$ & 87 & $18-21$ & $13-15$ & $22-25$ & $4-8$ & $7-10$ & $8-10$ & $24-30$ & $14-20$ & $11-16$ & $40-44$ & $22-28$ \\
\hline \multirow[t]{3}{*}{ D } & $8-9$ & $18-26$ Jun & 3 & 119 & $17-21$ & $13-15$ & $22-26$ & $4-8$ & $7-10$ & $8-11$ & $25-30$ & $12-20$ & $12-16$ & $39-45$ & $22-25$ \\
\hline & & & 4 & 83 & $18-21$ & $13-15$ & $22-26$ & $4-9$ & $7-9$ & $8-10$ & $25-30$ & $14-19$ & $11-15$ & $40-45$ & $22-25$ \\
\hline & & & $3+4$ & 202 & $17-21$ & $13-15$ & $22-26$ & $4-9$ & $7-10$ & $8-11$ & $25-30$ & $12-20$ & $11-16$ & $39-45$ & $22-25$ \\
\hline \multirow[t]{3}{*}{$E$} & $10-11$ & 8-15 Jun & 3 & 103 & $18-21$ & $13-15$ & $22-26$ & $4-8$ & $7-9$ & $8-11$ & $26-31$ & $14-19$ & $11-16$ & $40-45$ & $22-25$ \\
\hline & & & 4 & 83 & $18-21$ & $12-15$ & $22-26$ & $5-8$ & $7-10$ & $8-11$ & $25-30$ & $15-19$ & $12-15$ & $40-45$ & $19-26$ \\
\hline & & & $3+4$ & 186 & $18-21$ & $12-15$ & $22-26$ & $4-8$ & $7-10$ & $8-11$ & $25-31$ & $14-19$ & $11-16$ & $40-45$ & $19-26$ \\
\hline
\end{tabular}

juveniles and during the prespawning period. Thus, samples for this study were collected on the inshore and offshore spawning grounds during the spawning period. It was not always possible to collect samples in all parts of the stock areas (e.g. Labrador coast), but, where possible, collections were made at more than one location in a stock area and the data were combined.

All significant $x^{2}$ values in the text and tables refer to at least the $5 \%$ probability level (i.e. $P \leqslant 0.05$ ) of significance in the $B^{2}$ and $G^{2}$ analyses, and multiple comparisons were conducted by the Bonferroni procedure (Morrison, 1976) unless otherwise stated. The paired comparisons of the five groups of samples (A, B, C, D and $E$ ) were analyzed by the $B^{2}$ and $G^{2}$ procedures for the characters considered individually as well as collectively. As explained by Bowering and Misra (1982), the computer program ensures that no expected cell frequency of the "group $\times$ class" layout is less than the value assigned to the variable "AMIN". Snedecor and Cochran (1967, p. 235) suggested that the $x^{2}$ test is accurate enough if the smallest expectation is at least 1 , and this value was assigned to "AMIN" in every analysis of comparisons presented in this paper. This resulted in collapsing of the original $S_{i+1}$ classes into smaller numbers of classes. The classes thus formed were used in all statistical analyses and in the histograms of Fig. 2.

\section{Results}

\section{Comparisons based on separate age-groups}

For the meristic characters considered individually by age-group, none of the paired comparisons of groups $A$ to $E$ was significant for characters $1,2,4,6,7$, 10 and 11 of 3 -year-old capelin and for characters 2,3 ,
$4,5,6,7,9$ and 11 of 4 -year-old fish in the $B^{2}$ and $G^{2}$ analyses. Therefore, these characters were omitted in the analyses of paired comparisons of the groups based on collective contributions of the characters. Values of $\mathrm{B}^{2}, \mathrm{G}^{2}$, actual $x^{2}$, and normalized $x^{2}$ are tabulated for the remaining four characters of age 3 capelin and three characters of age 4 capelin (Table 2). The values of $B^{2}$ and $G^{2}$ were generally similar in each comparison. Also, the ranks for paired comparisons, determined from normalized $x^{2}$ values, were the same for the $B^{2}$ and $G^{2}$ analyses. Mean ranks (based on values for ages 3 and 4 in Table 2) for groups $A$ to $E$ were $3.8,5.0,8.4,4.6$ and 5.8 respectively.

For individual and combined characters, the significance of the paired comparisons, based on the $B^{2}$ and $G^{2}$ analyses, are given in Table 3 . Chi-square values for age 3 and/or age 4 capelin were significant $(P<0.05)$ for all paired comparisons of groups except the first (A, B). For age 3 capelin, only the correlation between characters 8 and 9 was significant in each of the five groups (Table 3 ). Therefore, $B^{2}$ and $G^{2}$ analyses were conducted by using a multiple classification base for these two characters. The multiple combination resulted in a severe collapsing of classes of the two-way layout. This may have occurred for two reasons. (1) There was severe disparity of sample sizes (Table 1), one sample (C) being small with only 42 age 3 and 45 age 4 capelin. When two characters are correlated, larger frequencies in a two-way (group $\times$ class) layout will occur in the northwest-southeast diagonal and these will decrease away from this diagonal. In the collapsing procedure of Bowering and Misra (1982), it is obvious that, when frequencies are distributed in this manner, the greater the disparity of sample sizes, the more severe will be the collapsing. (2) The correlation between the two characters was not strong (correlation coefficients were in the range of $0.58-0.78$ ). 
TABLE 2. Matrices of $B^{2}$ (below diagonal) and $G^{2}$ (above diagonal) values for four meristic characters in age 3 capelin and three characters in age 4 capelin of five groups of samples from the Newfoundland area, with corresponding $x^{2}$ and normalized $x^{2}$ values ( $d f=14$ and 10 for ages 3 and 4 respectively.)

\begin{tabular}{|c|c|c|c|c|c|}
\hline Group & A & $\mathrm{B}$ & $\mathrm{C}$ & $\mathrm{D}$ & $\mathrm{E}$ \\
\hline \multicolumn{6}{|c|}{ Age 3 (characters $3,5,8,9$ ) } \\
\hline$A$ & $\begin{array}{l}\mathrm{B}^{2} \text { or } \mathrm{G}^{2} \\
x^{2} \text { (actual) } \\
x^{2} \text { (norm.) }\end{array}$ & $\begin{array}{c}0.429 \\
24.49 \\
1.75\end{array}$ & $\begin{array}{c}1.879 \\
51.97 \\
3.71\end{array}$ & $\begin{array}{c}0.911 \\
43.91 \\
3.14\end{array}$ & $\begin{array}{c}1.000 \\
45.35 \\
3.24\end{array}$ \\
\hline B & $\begin{array}{c}0.440 \\
25.12 \\
1.79\end{array}$ & - & $\begin{array}{c}1.385 \\
47.78 \\
3.41\end{array}$ & $\begin{array}{c}0.710 \\
52.25 \\
3.73\end{array}$ & $\begin{array}{c}0.807 \\
54.21 \\
3.87\end{array}$ \\
\hline $\mathrm{C}$ & $\begin{array}{c}1.972 \\
54.54 \\
3.90\end{array}$ & $\begin{array}{c}1.458 \\
50.28 \\
3.59\end{array}$ & - & $\begin{array}{c}2.265 \\
70.30 \\
5.02\end{array}$ & $\begin{array}{c}2.765 \\
82.48 \\
5.89\end{array}$ \\
\hline $\mathrm{D}$ & $\begin{array}{c}0.954 \\
45.97 \\
3.28\end{array}$ & $\begin{array}{c}0.750 \\
55.16 \\
3.94\end{array}$ & $\begin{array}{c}2.421 \\
75.14 \\
5.37\end{array}$ & - & $\begin{array}{c}0.197 \\
10.87 \\
0.78\end{array}$ \\
\hline$E$ & $\begin{array}{c}1.053 \\
47.73 \\
3.41\end{array}$ & $\begin{array}{c}0.856 \\
57.48 \\
4.11\end{array}$ & $\begin{array}{c}2.947 \\
87.91 \\
6.28\end{array}$ & $\begin{array}{c}0.201 \\
11.08 \\
0.79\end{array}$ & - \\
\hline \multicolumn{6}{|c|}{ Age 4 (characters $1,8,10)$} \\
\hline$A$ & $\begin{array}{l}\mathrm{B}^{2} \text { or } \mathrm{G}^{2} \\
x^{2} \text { (actual) } \\
x^{2} \text { (norm.) }\end{array}$ & $\begin{array}{l}0.074 \\
3.87 \\
0.39\end{array}$ & $\begin{array}{c}1.576 \\
43.16 \\
4.32\end{array}$ & $\begin{array}{l}0.229 \\
8.71 \\
0.87\end{array}$ & $\begin{array}{c}0.285 \\
11.39 \\
1.14\end{array}$ \\
\hline B & $\begin{array}{l}0.076 \\
3.98 \\
0.40\end{array}$ & - & $\begin{array}{c}1.310 \\
48.41 \\
4.84\end{array}$ & $\begin{array}{c}0.303 \\
17.97 \\
1.80\end{array}$ & $\begin{array}{c}0.275 \\
17.67 \\
1.77\end{array}$ \\
\hline c & $\begin{array}{c}1.696 \\
46.45 \\
4.65\end{array}$ & $\begin{array}{c}1.405 \\
51.94 \\
5.19\end{array}$ & - & $\begin{array}{c}1.234 \\
36.00 \\
3.60\end{array}$ & $\begin{array}{c}1.906 \\
57.80 \\
5.78\end{array}$ \\
\hline $\mathrm{D}$ & $\begin{array}{l}0.240 \\
9.10 \\
0.91\end{array}$ & $\begin{array}{c}0.316 \\
18.70 \\
1.87\end{array}$ & $\begin{array}{c}1.334 \\
38.92 \\
3.89\end{array}$ & - & $\begin{array}{c}0.818 \\
35.87 \\
3.59\end{array}$ \\
\hline$E$ & $\begin{array}{c}0.295 \\
11.76 \\
1.18\end{array}$ & $\begin{array}{c}0.285 \\
18.31 \\
1.83\end{array}$ & $\begin{array}{c}2.043 \\
61.94 \\
6.19\end{array}$ & $\begin{array}{c}0.854 \\
37.45 \\
3.75\end{array}$ & - \\
\hline
\end{tabular}

Because severe collapsing weakens the sensitivity of $x^{2}$ analysis (Snedecor and Cochran, 1967), the generalized-distance analysis, employing multiple combined classification, was not carried further.

For the five meristic characters of age 3 capelin, the order of mean ranks and the magnitudes (in parentheses) from the $G^{2}$ and $B^{2}$ analyses were $Y_{9}(25.0$, 24.9), $Y_{8}(24.2,24.4), Y_{3}(16.7,16.6)$ and $Y_{5}(16.1,16.1)$, the relative importance of the characters in both analyses being in the same order. The values for characters 8 and 9 were approximately equal, and these characters were the most important ones for separating groups of age 3 capelin. The percent frequencies of characters 8 and 9 are illustrated in Fig. 2 ( and II).

For the three meristic characters of age 4 capelin, the order of mean ranks and the magnitudes (in parentheses) for the $G^{2}$ and $B^{2}$ analyses were $Y_{1}(19.3,18.9)$,
TABLE 3. Significant paired comparisons $(X)$ based on $B^{2}$ and $G^{2}$ analyses for various characters in five groups of age 3 and age 4 capelin.

\begin{tabular}{|c|c|c|c|c|c|c|c|c|c|}
\hline \multirow{2}{*}{$\begin{array}{c}\text { Group } \\
\text { pair }\end{array}$} & \multicolumn{5}{|c|}{ Age 3 characters } & \multicolumn{4}{|c|}{ Age 4 characters } \\
\hline & 3 & 5 & 8 & 9 & All & 1 & 8 & 10 & All \\
\hline \multicolumn{10}{|l|}{$A, B$} \\
\hline$A, C$ & & & & $x$ & $x$ & & $x$ & & $x$ \\
\hline$A, D$ & & & $x$ & & $x$ & & & & \\
\hline$A, E$ & & & $x$ & & $x$ & & & & \\
\hline $\mathrm{B}, \mathrm{C}$ & $x$ & & & $x$ & $x$ & $x$ & $x$ & & $x$ \\
\hline $\mathrm{B}, \mathrm{D}$ & & $x$ & & $x$ & $x$ & & & & \\
\hline $\mathrm{B}, \mathrm{E}$ & & $x$ & $x$ & & $x$ & & & & \\
\hline$C, D$ & $x$ & & $x$ & $x$ & $x$ & & $x$ & & $x$ \\
\hline $\mathrm{C}, \mathrm{E}$ & $x$ & & $x$ & $x$ & $x$ & $x$ & $x$ & & $x$ \\
\hline $\mathrm{D}, \mathrm{E}$ & & & & & & $x$ & & $x$ & $x$ \\
\hline
\end{tabular}

$Y_{8}(14.4,14.8)$ and $Y_{10}(12.8,12.8)$, the relative importance of the characters in both analyses being in the same order. Characters 1 and 8 were the most important for distinguishing between groups of age 4 capelin, and their percent frequencies are shown in Fig. 2 (III and IV).

\section{Comparisons based on age-groups combined}

Analysis of the differences between ages 3 and 4 capelin in each of the five groups ( $A$ to $E$ ) indicated that characters 8 and 9 differed significantly for group $A$, characters 5,8 , and 9 differed for group $B$, characters 2 , 8 and 10 differed for group $C$, and there were no significant differences between the ages for groups $D$ and $E$. There being no consistent difference between agegroups with respect to any one of the 11 characters considered collectively, it was decided to compare the five groups ( $A$ to $E$ ), with data for the two ages combined on the basis of all 11 characters and also characters $1,3,4,6,7$ and 11 , which consistently exhibited no significant differences between ages in all five groups of samples.

Use of eleven characters. The generalizeddistance analysis, where characters were considered independently for combined ages, resulted in similar $\mathrm{G}^{2}$ and $\mathrm{B}^{2}$ values. The mean ranks and the magnitudes (in parentheses) for the $\mathrm{G}^{2}$ and $\mathrm{B}^{2}$ analyses were $Y_{8}(78.1,78.4), Y_{9}(65.1,65.1), Y_{6}(64.1,63.8), Y_{1}(59.3$, 59.7), $Y_{4}(58.6,58.6), Y_{3}(55.3,55.2), Y_{10}(52.6,52.8)$, $Y_{5}(48.9,48.9), Y_{2}(47.3,46.9), Y_{7}(44.9,44.7)$ and $Y_{11}(36.3,36.4)$, the relative importance of the characters in both analyses being in the same order. Character 8 followed by characters 9 and 6 were the most important ones for separating the five groups with ages combined.

With respect to the paired comparisons for groups $A$ to $E$ from the $G^{2}$ and $B^{2}$ analyses, no pairs differed significantly for characters $2,4,7,10$ and 11 . Paired comparisons were significant ( $X$ in Table 4 ) for individual characters and groups of characters except pairs 


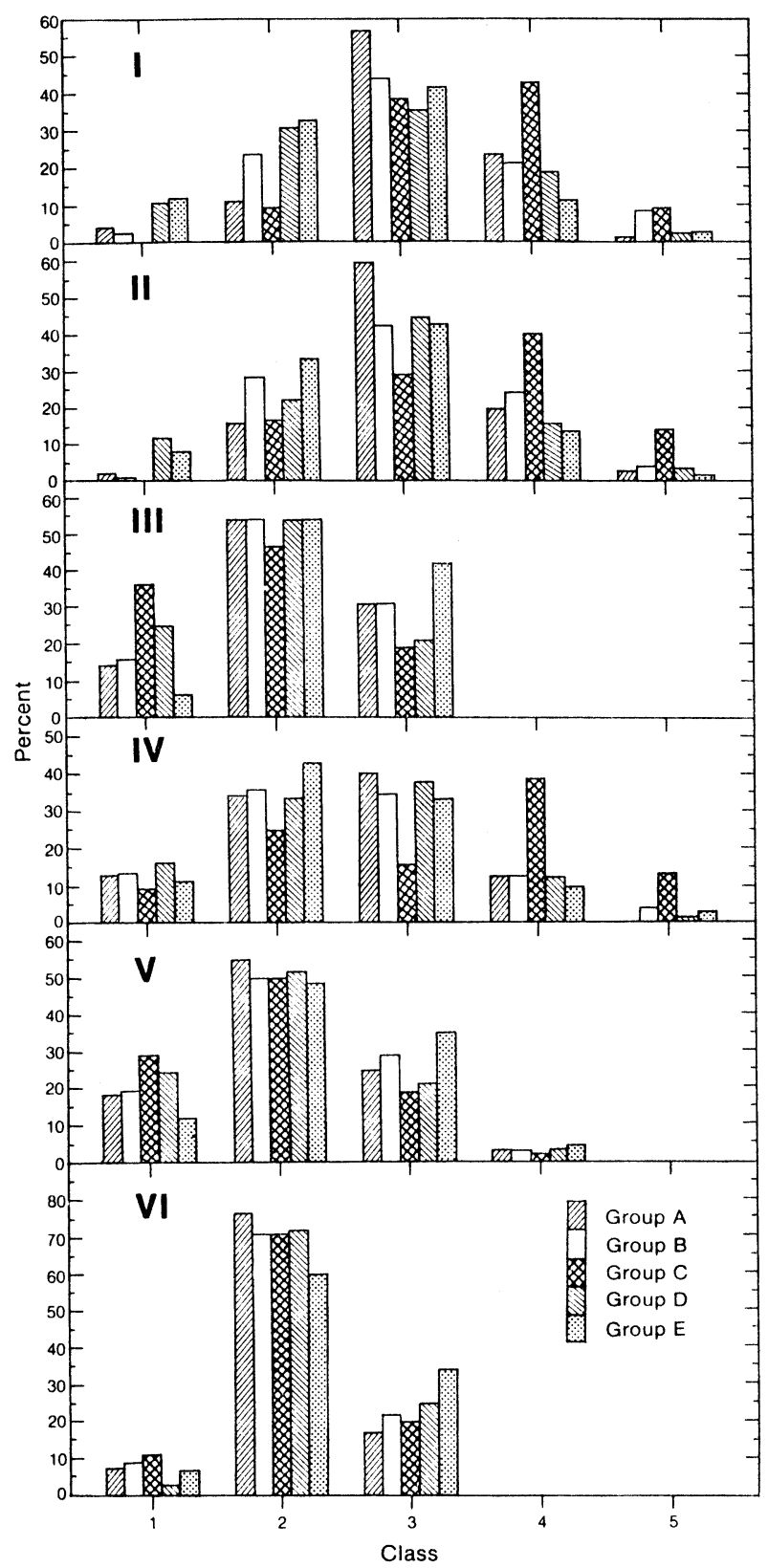

Fig. 2. Percent frequency of meristic counts by class for the two most important characters identified in each analysis of five groups $(A-E)$ of capelin from different parts of the Newfoundland area: $I$, dorsal secondary caudal fin-rays (character 8 ) of age 3 fish; II, ventral secondary caudal fin-rays (character 9 ) of age 3 fish; III, left pectoral fin-rays (character 1 ) of age 4 fish; IV, dorsal secondary caudal fin-rays (character 8 ) of age 4 fish; $\mathbf{V}$, left pectoral fin-rays (character 1 ) of ages 3 and 4 fish; VI, upper gillrakers (character 6 ) of ages 3 and 4 fish.

$(A, B),(A, D)$ and $(B, D)$. When the data for these pairs were analyzed independently (i.e. excluding the other three groups in each case), group A differed ( $S$ in Table 4) for character 4 and groups $A$ and $D$ differed for character 5 . From the normalized $x^{2}$ values, the mean ranks for groups $A$ to $E$ were determined to be 4.8, 4.0, $8.5,4.2$ and 6.0 respectively.
TABLE 4. Significant paired comparisons $(X)$ by the Bonferroni procedure for various characters in five groups of capelin with ages combined ( $S$ indicates significance when the samples were analyzed independently).

\begin{tabular}{|c|c|c|c|c|c|c|c|c|c|}
\hline \multirow{2}{*}{$\begin{array}{c}\text { Group } \\
\text { pair }\end{array}$} & \multicolumn{9}{|c|}{ Ages 3 and 4 characters combined } \\
\hline & 1 & 3 & 4 & 5 & 6 & 8 & 9 & $1,3,4$ & 1,6 \\
\hline$A, B$ & & & s & & & & & & \\
\hline$A, C$ & & & $S$ & & & $x$ & $x$ & $x$ & \\
\hline$A, D$ & & & & $S$ & & & & & \\
\hline$A, E$ & & & & $x$ & $x$ & & & $x$ & $x$ \\
\hline$B, C$ & & $S$ & $S$ & & & $x$ & $x$ & $x$ & \\
\hline$B, D$ & & & & & & & & & \\
\hline$B, E$ & & & & & $x$ & & & $x$ & $x$ \\
\hline C,D & & $S$ & & & & $x$ & $x$ & $x$ & \\
\hline$C, E$ & $x$ & $x$ & & & & $x$ & $x$ & $x$ & $x$ \\
\hline $\mathrm{D}, \mathrm{E}$ & $x$ & & & & & & & & $x$ \\
\hline
\end{tabular}

In all five groups, the following pairs of characters were significantly correlated: $(1,6),(5,6),(5,8)$ and $(8,9)$. Multiple classification, using the criterion AMIN $=1$, severely collapsed the classes for combinations 1 and 6 ( $97 \%$ of the total number of fish being confined to just two classes) and for combinations 5 and 6 (all fish in just one class). Therefore, paired comparison of groups was conducted for a multiple classification of characters 5, 8 and 9 combined. This analysis of combined characters and the multiple classification analysis of characters 1, 3, 4 and 6 did not add any new information.

Use of characters 1, 3, 4, 6, 7 and 11 only. The generalized-distance analysis again resulted in similar $G^{2}$ and $B^{2}$ values. The order of mean ranks and the magnitudes (in parentheses) for $G^{2}$ and $B^{2}$ were $Y_{6}(35.1,35.1), Y_{1}(34.8,34.8), Y_{4}(33.4,33.3), Y_{3}(29.3$, 29.4), $Y_{7}(29.3,29.4)$ and $Y_{11}(21.1,21.0)$, the relative importance of the characters in both analyses being in the same order, as was the case when all characters were used. Character 6 was the most important one, with characters 1 and 4 being second and third in importance. To illustrate the difference in characters, the percent frequencies of the two most important ones ( 1 and 6$)$ are shown in Fig. 2 (V and VI).

With regard to the paired comparisons of groups from the $G^{2}$ and $B^{2}$ analyses, no pairs of groups differed significantly for characters $3,4,7$ and 11. The analysis for the collective contribution of the remaining two characters identified only two sets of the five groups (i.e. group $E$ and groups $A-D$ ), there being no significant difference for any pair of groups $A, B, C$ and $D$. When the data for pairs $(A, B),(B, D)$ and $(A, D)$ were analyzed independently (i.e. excluding the other three groups in each case), group $A$ and $B$ differed for character 4 (as stated previously) and groups $A$ and $D$ differed significantly for all characters considered collectively. When the pairs $(A, C),(B, C)$ and $(C, D)$ were analyzed in this manner, groups $A$ and $C$ differed for character 4 ( $S$ in Table 4 ) and nearly so for all characters (estimated $x^{2}=31.0$, critical $x^{2}=31.4$, $\mathrm{df}=20$ ), 
groups $B$ and $C$ differed for characters 3 and 4 and for all characters considered collectively, and groups $\mathrm{C}$ and $D$ differed for character 3 and for all characters considered collectively. Mean ranks for groups $A$ to $E$ were $3.8,4.5,6.8,4.5$ and 8.0 respectively.

\section{Discussion}

The methodology used in this paper, considered by the authors and by Bowering and Misra (1982) to be more appropriate for meristic data than that previously used by Carscadden and Misra (1980), has been applied to the same meristic data reported elsewhere by the latter authors. The results of the present analysis, with age-groups treated separately and combined, substantiate the results of the previous analysis in that capelin which spawn on the Southeast Shoal (group C) and along the west coast of Newfoundland (group E) continued to be identified as separate stocks. The inshore spawning stocks of Labrador-Northeast Newfoundland (group A), northern Grand Bank-Avalon (group B) and St. Pierre-Green Bank (group D), which could not be identified as separate stocks in the former treatment (Carscadden and Misra, 1980), continued to be problematic, although there were indications that these stock designations may be valid. However, these latter groups (A, B and D) could not be separated without more detailed analysis of the data, such as analyzing age-groups separately or using independent paired comparisons. For example, when age-groups were considered separately, the stock off southern Newfoundland (group D) was identified as a separate stock but the two stocks (groups $A$ and $B$ ) which extends from Labrador along eastern Newfoundland and including the northern Grand Bank could not readily be separated. Interestingly, independent paired comparison with age-groups combined showed a significant difference between these stocks for character 4 (pyloric caecae) in both $B^{2}$ and $G^{2}$ analyses, indicating that these stocks were indeed different.

No single character emerged from the comparison of ranks and magnitudes of $B^{2}$ and $G^{2}$ as the most important for separating the stocks. However, characters 1 (left pectoral fin-rays), 6 (upper gillrakers), 8 (dorsal secondary caudal fin-rays) and 9 (ventral secondary caudal fin-rays) appeared to be the most important ones over the range of the comparisons tested.

The success of separating the capelin stocks of western Newfoundland (group E) and Southeast Shoal (group C) from the other groups and the problems of separating groups $A, B$ and $D$ from each other by meristics may not be surprising in view of the possible environmental factors that may influence the determination of meristic characters during the early develop- mental stages, as briefly reviewed by Bowering and Misra (1982). The capelin stock on the Southeast Shoal is known to spawn on bottom (approximately $50 \mathrm{~m}$ depth) where water temperatures are $2^{\circ}$ to $4^{\circ} \mathrm{C}$ (Pitt, 1958). The other stocks are comprised mainly of capelin which spawn on the beaches and prefer water temperatures of $5.5^{\circ}$ to $8.5^{\circ} \mathrm{C}$, although some spawn in deeper water near the beaches (Templeman, 1948). The capelin along western Newfoundland are reported to spawn more in deeper water, because the water in shallow beach areas warms very rapidly due to the reduced influence of the Labrador Current (Jangaard, 1974). Other environmental factors, such as oxygen (Garside, 1966; Tåning, 1952) and light (Lindsay, 1958) have been shown to influence meristic characters. It is probable that all of these environmental factors differ to some extent among such diverse spawning areas during both the spawning and developmental periods. In the case of beach spawning, environmental factors may even differ at low-, mid- and high-tide levels (Frank and Leggett, 1981). Meristic characters are thought to have different critical periods during which the number for each character is determined (Tåning, 1952; Molander and Swedmark, 1957). Clearly, the effects of the environment on determination of meristic characters is complex and these effects are further complicated by the fact that meristic characters in most fish are genetically controlled by a multifactor system (Barlow, 1961). Without detailed knowledge of the development of meristic characters in capelin relative to environmental factors, it is impossible to establish a biological basis for the differences in meristic characters identified in this paper. However, in the case of dorsal secondary caudal fin-rays of age 3 fish, it is interesting to note that there was a greater frequency of higher counts in capelin from the Southeast Shoal (group C). For left pectoral fin-rays of age 4 fish, there was a greater frequency of lower counts in capelin from the Southeast Shoal and higher counts in capelin from western Newfoundland.

The capelin on the Southeast Shoal may be further isolated from those of other areas during their early life history by the current system in the area. In a recent review, Petrie and Anderson (1983) confirmed earlier work of Smith et al. (1937) who reported that the westward branch of the Labrador Current moves southward over the Grand Bank and then westward along the edge of the shelf, creating an anticyclonic gyre over the area centered at $44^{\circ} 30^{\prime} \mathrm{N}, 50^{\circ} \mathrm{W}$ (see fig. 2 of Petrie and Anderson, 1983). This location coincides with the capelin spawning grounds on the Southeast Shoal.

\section{Acknowledgements}

The assistance of D. Kelder and B. Gellately, who performed the computations, is gratefully acknowledged. 


\section{References}

BARLOW, G. W. 1961. Causes and significance of morphological variation in fishes. Syst. Zool., 10: 105-117.

BOWERING, W. R., and R. K. MISRA. 1982. Comparisons of witch flounder (Glyptocephalus cynoglossus) stocks of the Newfoundland-Labrador area, based upon a new multivariate analysis method for meristic characters. Can. J. Fish. Aquat. Sci., 39: 564570.

CAMPBELL, J. S., and G. H. WINTERS. 1973. Some biological characteristics of capelin, Mallotus villosus, in the Newfoundland area. ICNAF Redbook, 1973(III): 137-144.

CARSCADDEN, J. E., and R. K. MISRA. 1980. Multivariate analysis of meristic characters of capelin (Mallotus villosus) in the Northwest Atlantic. Can. J. Fish. Aquat. Sci., 37: 725-729.

FAIRBAIRN, D. J. 1981. Which witch is which? A study of the stock structure of witch flounder (Glyptocephalus cynoglossus) in the Newfoundland region. Can. J. Fish. Aquat. Sci., 38: 782-794.

FRANK, K. T., and W. C. LEGGETT. 1981. Prediction of egg development and mortality rates in capelin (Mallotus villosus) from meteorological, hydrographic, and biological factors. Can. J. Fish. Aquat. Sci., 38: 1327-1338.

GARSIDE, E. T. 1966. Developmental rate and vetebral number in salmonids. J. Fish. Res. Board Can., 23: 1537-1551.

JANGAARD, P. M. 1974. The capelin (Mallotus villosus) biology, distri- bution, exploitation, utilization, and composition. Bull. Fish. Res. Board Can., 186, $70 \mathrm{p}$.

KURCZYNSKI, T. W. 1970. Generalized distance and discrete variables. Biometrics, 26: 525-534.

LINDSAY, C. C. 1958. Modification of meristic characters by light duration in kokanee, Oncorhynchus nerka. Copeia, 1958: 134-136.

MOLANDER, A. R., and M. M. SWEDMARK. 1957. Experimental investigations on variations in plaice (Pleuronectes platessa L.). Rep. Inst. Mar. Res. Lysekil. (Biol)., No. 7, 45 p.

MORRISON, D. F. 1976. Multivariate analysis. McGraw-Hill Book Co., New York, NY, $415 \mathrm{p}$.

PETRIE, B., and C. ANDERSON. 1983. Circulation on the Newfoundland continental shelf. Atmosphore-Ocean, 21: 207-226.

PITT, T. K. 1958. Distribution, spawning and racial studies of the capelin, Mallotus villosus Müller, in the offshore Newfoundland area. J. Fish. Res. Board Can., 15: 275-293.

SMITH, E. H., F. M. SOULE, and O. MOSBY. 1937. The Marion and General Greene expeditions to Davis Strait and Labrador Sea. Bull. U.S. Coast Guard, 19, 259 p.

SNEDECOR, G. W., and W. G. COCHRAN. 1967. Statistical methods. lowa State Univ. Press, Ames, lowa, $593 \mathrm{p}$.

TÅNING, A. V. 1952. Experimental study on meristic characters in fishes. Biol. Rev., 27: 169-193.

TEMPLEMAN, W. 1948. The life history of the capelin (Mallotus villosus Müller) in Newfoundland waters. Res. Bull. Dept. Natural Resources, Nfld., 17: $151 \mathrm{p}$. 
